\title{
CONCEPTUAL FRAMEWORK OF SOCIAL ADAPTATION
}

\author{
Venelin Terziev \\ Academician of the Russian Academy of Natural History, Moscow, Russia, Prof. \\ D.Sc. (Ec.), D.Sc. (National Security), D.Sc. (Social Activities), Ph.D., National Military University, \\ Veliko Tarnovo, Bulgaria; University of Rousse, Rousse, Bulgaria, terziev@skmat.com
}

\begin{abstract}
This paper, originating from the understanding and approaches to the term „adaptation“, explores and analyses the stages of the social adaptation process of military personnel, discharged from service, which along with getting to know the psychological and professional aspects of the process allows the elaboration of a practical model of social and psychological adaptation of this population category. The scientific aspirations of the authors of this paper are focused on the specific characteristics of military service and the specific competences, which require the implementation of specific methods and means of professional orientation, preparation for settling and acquiring a new profession in the changed living environment.
\end{abstract}

Keywords: conceptual framework, social adaptation, adaptation.

\section{CONCEPTUAL FRAMEWORK OF SOCIAL ADAPTATION}

Conceptuality of social adaptation is predetermined by the fact that it is a subject of study by different scientific areas, which in itself is a prerequisite for the applicability of various approaches to its definition. In the context of human adaptability to changes in the social environment, one of the main approaches to the study of its nature is sociological.

The sociological approach to examination of adaptation is presented in the works of prominent Western sociologists E.Dyurkem, M.Weber, T.Parsans and R.Martan. According E.Dyurkem, adaptation is the adjustment of the internal organization of the individual to the existing norms of the society. On the individual level adaptation consists in the adoption by the individual of the dominant public morality, awareness of his duty to society, which manifests itself in his thoughts, goals, actions. On the society level, adaptation is mainly reflected in the very existence of the norms themselves. Quintessence of adaptation is the existence of public morality shared by all members of society. The norms are primary, „positive”, and the individual and his personal consciousness are secondary. Functionally the adaptation of the individual is a process of absorption, of „interiorization” of the existing norms.Any deviation from the adoption of these norms by the individual is social pathology. The lack of norms, their defects, vagueness- this is pathology of society. Although E.Dyurkem does not use the term „adaptation”, his scale „normpathology” is completely identical with the concepts of adaptation-de-adaptation. The positivistic understanding of adaptation as blind acceptance and learning by the individual of the conditions of the social environment, corresponds with the 
Lamarck's direct adaptation. The role of the individual is completely ignored, and adaptation is defined as a process opposite to social progress.

Narrowness of positivism is successfully overcome by M.Weber. He does not object to the socio-normative determination of the adaptation of the individual, but believes that this is not the only, and not always the best approach for the individual. If social norms coincide with the interests of the individual, he follows them, if they do not, he rejects them. Criterion for adaptation is rationality, effectiveness in achieving the objectives. M.Weber demonstrates the unity ofindividual and group level of adaptation and reveals their natural contradictions. Variability of norms, models of behavior, approaches to achievement of objectives, incite the individual to active creative action. It is noteworthy that it is not the social norms that create the adaptation of the individual, but it is the individual in the process of his adaptation who evaluates, modifies, develops the social norms. Thus, according M.Weber, adaptation is not just a way of existence of the individual, but also one of the mechanisms of social progress. The views of M.Weber launch a pragmatic approach in understanding the adaptation.

Despite that, the individualism of the objectives and the pursuit of maximum rationality in achieving them according to $\mathrm{M}$. Weber violate the public consent, oppose the interests of the individual tothe public interest. From the point of view of T.Parsans, individual rationality as a main criterion of adaptation leads to instability, to provoking social conflicts. Public progress according T.Parsans is a mutual compromise, an integration. His concept of "equilibrium of society" consists in "the balance between the mutual expectations of the individual and the social environment". According T.Parsans, adaptation is an equilibrium and stabilization, public tranquility, equally useful both for the individual and for the socium. The views of $T$. Parsans correspond with the most common, both in sociology and in other sciences, homeostatic approach to understanding adaptation.

However, as evidenced by R.Merton, society is not balanced, as this is incompatible with the dialectics of development. The social structure is internally contradictory and dynamic, it is subject to constant transformations even in periods of relative social stability. Therefore adaptation of the individualalso happens in conditions of instability and conflicts. Institutionalized approaches to objectives achievementdo not always lead to the usual result. The society again transfers adaptation to the individual level- every individualfollows his own path or way of adaptation, adequate to his normative organization. R. Merton even developed a classification of the main approaches to individual adaptation, according to both setting of goals and achieving them, proving that the adaptation is individually-typical. What is adaptation for one individualin a certain moment, couldbe not an adaptationfor another individual in another moment, in equal or unequal conditions. Social laws and norms help the individual to achieve adaptation, and the same time prevent him from achieving it. Adaptation according to R.Merton is following the rules and at the same time disavowing them. It is both rational behavior, leading to the achievement of individual goals, and irrational behavior, consciously depriving the individual of this opportunity. This is both cooperation with the socium, and a rebellion against it. Therefore, the adaptation of the individual according to prominent sociologists is „normativity”, „rationality”, „equilibrium”, „individuality”. As a result, the concept of adaptation has no single, clear, widely recognized understanding, definition, criteria, indicators. Despite that, one can trace the continuity of some typical systems, views on this social process and presented them in the form of small classification. Similar attempt was made in the monograph of L.V.Korel where six different concepts of adaptation are distinguished:

- Adaptation is used to denote the process by which the subject adapts to the new environment ("accommodative/adaptive variability");

- Adaptation means the result of the adaptation process;

- Adaptation is associated with certain particular goal towards which the subject strives: „to stay alive", to achieve material prosperity, to improve his social status, etc. (teleologicity and pragmatism of adaptation);

- Adaptation (adaptability) implies conformity between goals and achieved in the process of the activity results;

- Adaptation is used to define the ratio of the equilibrium (relative harmony), which is established between the subject and the environment (homeostatic approach);

- Adaptation is a process which not only complies with the homeostatic laws, but also provides an opportunity for development of the subject of adaptation (homeorezis).

The classification of L.V.Korel is sufficiently complete. Made distinct is the concept of adaptation as accommodation, pragmatism, homeostasis, development, but unifying two classification bases (content and 
process) in one concept, arouses some confusion, which, by the way, corresponds to the current state of the matter. Meaningful classification of the adaptation variants is offered by V.A. Petrovski who distinguishes homeostatic, hedonistic and pragmatic variants (Terziev, 2018a, pp. 228-236; Stefanov, Terziev, Banabakova, 2018b, pp. 93-102; Stefanov, Terziev, Banabakova, 2018c, pp. 111-119; Terziev, Stefanov, Banabakova, 2018d, pp. 120-131; Terziev, Stefanov, Banabakova, 2018e, pp. 132-148; Terziev, $2018 f$, pp. 213-227; Terziev, 2018g, pp. 237-247; Terziev, 2018h, pp. 256-265; Terziev, 2018i, pp. 266-276; Terziev, Latyshev, Georgiev, 2018j, pp. 248-255; Glushkov, Simeonov, Georgiev, 2018k, pp. 88-92; Banabakova, Georgiev, 2017a, pp. 37-47).

In the scientific literature are widely represented attempts to summarize the main systems of understanding the process of social adaptation, without being sufficiently comprehensive. In this vein, we study the sociological definition of the category adaptation. Only the term „adaptation” is not used. In most cases it is about „social adaptation”, different types of adaptation (socioeconomic, organizational and many others), or without any special instructions, adaptation again means social adaptation. Hence, adaptation is always social, because the types of adaptations, distinguished in the various sociological studies, are varieties of social adaptation. The created situation is completely legitimate and justified as the object of these studies is the adaptation of the individual or of certain social formations: groups, communities, institutions, organizations, the whole society.

In the scientific literature there are more than two hundred different definitions of social adaptation. Therefore, we will not go through the different definitions, but rather analyze the elements of interest to us, building those definitions. Here we shall only point out one of the modern definitions: „Social adaptation is the accommodation of the individual or the social group to the social environment, in the course of which the requirements and expectations of participating in it subjects are coordinated".

Social adaptation is comprehensive, continuous, dynamic, relatively stable social process of establishing correspondence between the aggregate level of current at a certain time needs of the individual and the level of their satisfaction, defining his continuous development. Adaptation cannot be defined as a state. This would mean a possibility for a state of „non-adaptation” or lack of adaptation, and would contradict its continuity and dynamism. Determination of adaptation as a property is more applicable to the general biological concept of adaptation, as a characteristic of all living nature, the individual groups of organisms, because it does not reveal the social content of adaptation. „The ability to adapt is a universal property of living nature". Adaptation is defined as a mechanism to ensure life in very adverse to the organism and therefore relatively rare conditions. Adaptation is a specific biological phenomenon associated with the vital activity of the organism in inadequate conditions of the environment, preserving the optimal ratio of vital functions and the capabilities of work and learning. It is interesting to note that similar living conditions can also be characteristic for the traditional production.

Very often adaptation is defined as a "result". Adaptation is the result of balance of mutual expectations of the individual and social institutions, to which he is subject. Determination of adaptation as a result indicates its boundaries, completeness, feasibility, interruptible, which contradicts the function of ensuring the development of the individual, including his social development. Interpretation of social adaptation as a result is based on the homeostatic tradition of its concept (K.Levin, T.Parsons, L.Festinger). Many researchers attempt to combine the understanding of social adaptation as a process and as a result. For example, M.A.Shabanova defines the social adaptation as „a process and result of interaction of the individual (the group) with dramatically changing social environment, during which the requirements and expectations of both sides are gradually aligned".

Any deviation from the concept of adaptation as a process, leads to absolutization of its specific manifestations, inevitably opposes the private, situational, individual goals and problems of the general biological and social process. Only in the form of a process is the individual both subject and object of its formation. American sociologist W.R.Sop defines adaptation as a process, at that in a „pure form”, without any clarifying terms. He defines social adaptation as a social process for reasons which are:

First, the adaptation of the individual is always social. Sociality is the most important criterion for defining an individual. Its absence immediately questions the legitimacy of the defining a living being as a person, an individual. Lack of sociality or its total loss in the individual is virtually impossible. Even an individual who has lost (or was born without) his basic mental functions, such as consciousness, is socially adapted thanks to the efforts of other members of society. Thinking and behavior of the individual retain their sociality and even under conditions of full and continuous social deprivation, through memory, habits, skills. Therefore, sociality of the individual is contained both in his environment and within himself. In none of his deeds, can the individual becompletely separate and independent from society. We understand social adaptation much broader than it is generally accepted by individual studies, in which adaptation, as already mentioned, is 
seen as an interaction between the individual, the social group or institution, and the socium in its various manifestations. Even temporary separation from the socium, and even more opposing it, is dangerous for the individual.

Second, the adaptation of the individual always differs from the process of ordinary adaptation, response to stimuli. Adaptation of the individual is not only an adaptation of the particular individual (organism), social group, but also a cultural-historical process in which the individual is both subject and object of the given process. In the individual, in his psyche, behavior, there is nothing that cannot be found in the socium, that is not a manifestation, a reflection of his interests. Adaptation of the individual, its laws, its specific manifestations can be properly understood only in a social context, which should be the starting point for any scientific approach to the problem of adaptation. The very extent of aggregation of the problem certifies that no criterion can be a full expression of all possible explications of the process of social adaptation. Neither balance nor pleasure, nor normativity, nor rationality or some other „felicitous” discoveries constitute the quintessence of well-being both of the individual and the social organization, and cannot claim to be the sole criterion for adaptation as a social process.

The process nature of adaptation and social development are two sides of the same essence. Permanent social dynamics determines the continuity of the process of adaptation, which in turn is the starting material for the constant improvement of the social organization. The refusal adaptation to be seen as a social process inevitably leads to inadequate evaluation of its sources, mechanisms, various manifestations. An illusion is created of an opportunity and independence, or even opposition to the adaptation of the individual and the development of the socium. If the adaptation of the individual was not a social process, then the effectiveness of adaptive activity would decrease at times, and social organization would not have a reliable mechanism for global regulation and development.

Social adaptation is defined as the process of establishing „compliance”. Here we point out exactly how is compliance established, as the number of possible approaches to achieve it is hugeinteraction, immersion, learning, inclusion, accommodation, formation and many others. In each case, the individual can apply any of them, so the indication of a specific approach in defining social adaptation brings artificial restrictions which hamper the interpretation of the given process. With analyzing the different definitions of social adaptation, it becomes possible to trace the dynamics of changes in the use of the key concept of „adaptation”, understood as „accommodation”, „inclusion4, „interaction”. The most commonly used definition of social adaptation is ,interaction between the individual and the social environment”.

Social adaptation is defined as the correlation between the level of needs and the level of their satisfaction. In that reside the details of the whole definition in which the existing needs are satisfied and create new needs, at a qualitatively higher level. In general terms, this is the pattern of development of both the individual and of the socium, in which social adaptation plays the role of a characteristics of intensity of development. This is the most significant difference of the proposed definition from most of the definitions of social adaptation, existing in different social science disciplines.

Contemporary standard definition of social adaptation can be briefly expressed as „interaction between the individual and the social environment", while indicating the different specifics of this interaction and the levels of the social environment. Put another way, basis of the adaptation is not the direct confrontation between the individual and the socium, but their mutual compromise, adjustment. Keeping in mind the unity of the individual and the social environment, we can determine that the needs of the individual are a concentrated expression of the biological and social systems. Only through the mechanism of satisfaction of needs, is the biological development and socialization of the individual realized. Already E. Durkheim said that social norms exist and are alive only when interiorized by the individual. It is the needs of the individual that represent interiorized social norms. Therefore, the very needs of the individual (both social and biological) can in no way contradict (and respectively oppose) the socium, unlike the way of their fulfillment. Meeting the needs of the individual meets the interests and objectives of the socium, otherwise these needs would not had beenfixed in our genetic and social fund (social memory), and would not had been made available to the individual. The society is interested not in just the individual, but and in the individual who satisfies "his" needs and thus does his activity on reproduction and development of society itself. The successful execution of an activity is encouraged by pleasure, failure is punished by suffering. It turns out that satisfying the needs of the individual means "compliance with the socium", i.e. social adaptation. This is the main substantive moment, the starting point of this definition and of the whole concept of social adaptation. The dominant understanding of social adaptation is in the concept of opposition between the individual and the socium, the individual and the environment (in many cases needs can be met without the participation of this reality), while at the same time formulating the basic practical criterion for social adaptation- needs and their satisfaction. The opportunityfor distinguishinga simple and understandable criteria for adaptation is very 
useful in its subsequent measurement. It is the actual satisfaction of needs that is an essential criterion and the result of balance, inclusion, adaptation, rationality and even development. Needs, as well as their satisfaction are dynamic variables, because they can be updated, and each need in order to be satisfied requires a complex of factors. But the finding that social adaptation is in itself satisfaction of the needs of the individual or just a satisfaction (as in „satisfactory approach”) is correct, but insufficient.

The current at a given moment needs determine the adaptation. It is not enough to point out that adaptation is the satisfaction of the need of the individual, because the individual has many needs and their status and level of satisfaction are different. But not all needs are important to him in anyparticular moment, some (or one) are immediate, othersare not. If the need at a certain moment in time is not up to date, for the adaptation the condition and indicators of its satisfaction are irrelevant, no matter how vital it is. Therefore, not all needs determine the adaptation, but only the up to date ones. Depending on the degree of satisfaction of the current need it loses its meaning and is replaced by another.

This is very important, especially from point of view of the dynamics of social development. Formation in the individual of new needs is a long and inconspicuous process. This happens because the individual has a whole set of unrealized needs and the satisfied need is replaced by a long ago formed one. This process of forming of new needs stays in shadow and creates the illusion that it is not related to the adaptation, while the main result of social adaptation is the formation of new needs.

Adaptation is a process that determines the continuous development of the individual. Here the purpose of social adaptation is merely stated, as a social process bringing together the interests of the individual and the socium. It is the development of the individual which is the end result of the update, satisfaction and raising of the needs. Only through the development of the individual is realized social development, in which every individual is an elementary material "component" in the development of the wholesociety. Adaptation provides development of the individual in all, even extremely adverse conditions. The importance of understanding and defining the social adaptation as a function of the development of the individual is conditioned by the overindividuality of a certain social process, by the impossibility this process to be understood and interpretedcorrectly only on the level of the individual. Development of the individual is the purpose of adaptation, but not apurpose of the individual himself. Ontogenetic development of the individual is expressed in the increase and the rise of needs, while phylogenetic- in raising the level of the social organization and its culture.

Speaking of classifications of social adaptation, it is appropriate to divide them into procedural and objective. The traditional approach, whereby social adaptation is the result of changes in the environment, determines a greater number of types of adaptations, related to changes of its specific objects. Accordingly, in the names of the types of adaptations the object of adaptation is directly stated: social, socio-psychological, educational, professional, industrial, cultural, material, neighborhood-friendly, psychophysiological, organizational, economic, household and many other types of adaptation. In practice, the number of distinguished types of adaptations, corresponding to the objects of adaptation is infinite. The term "adaptation" alone, without indicating its type identification is usually not used, but is defined (using the above adjectives or prepositions: „of”, „in”, „to") the appropriateobject of adaptation- enterprise, social group, social role. Thus, the process of adaptation is put in dependence on the correct choice of the object of adaptation, and even under the most appropriate choice, the reality in question is reflected partly, as the particular object of adaptation extremely rarely can fully realize the adaptation process. At the same time, each object of adaptation affects its process systematically, i.e. both specific and non-specific, to the object, types of adaptations are realized.

The majority of studies on adaptation are based on the principle of separation of the object and its corresponding type of adaptation, the result of which is determining: „presence” or „absence”, or assessment for the particular type of adaptation, and a hypothesis about the causes and relevant recommendations are offered. The actuality of the individual type of adaptation, including with regard to the specific object of adaptation, for the studied subject of adaptation at the time of the study, is not taken into account.

study, is not taken into account. If the types of adaptations discriminated on the basis of the objects of adaptation are infinite, then according to other criteria there exist comprehensive classifications. It is about the classification, offered by I.A.Miloslavova:

According to the nature of the interaction between the subject of adaptation and the adaptive environment: adaptation in the form of accommodation and adaptation in the form of adaptation;

According to the type of adaptive environment to which the individual is adapting (or which he adapts to himself): production; matrimonial; neighborhood-friendly; political-legal; educational; 
According to the structural components of the adaptive environment: object-activity-related and personal;

According to the psychological content: pre-adaptation; de-adaptation; re-adaptation; desadaptation.

This classification is very widespread. Distinction between different types of adaptation is very popular among the different researchers of social process. The majority of researchers provide their own names for the types of adaptation, and their own classification. L.V.Korel attempts to unite the existing classifications for the types of adaptation, offering 30 criteria for differentiation of adaptation. Based on these criteria he separates 92 types of adaptation, but at the conclusion of its detailed description he states that this classification "is not fully complete”.

The separation of a wide number of various bases for classifying adaptation and the complexity of these classifications, speak about the ambiguity of the described by various authors process, about the uncertainty of its nature and foundations. This, however, does not stultify pointing out that "from point of view of a systematic approach it is important in the analysis of one or another type of adaptation, it to be viewed not in isolation, but in the context of other adaptation processes".

From the standpoint of the offered by us concept of social adaptation, the structuring of the process of adaptation by kinds, shapes, types, is conditional, and in the practical study of adaptation of the individual, is wrong. In practical studies, structuring is appropriate only in the study of the adaptive capability of the object.

Consequently, adaptation is not a set of these and other types of adaptation. It is a holistic process that is not limited to the sum of its constituent elements. It would be wrong to say that the level of sociopsychological adaptation is low and the level of the life adaptation is high, as these are two sides of the same process, although the extent of their influence and level of satisfaction are different. To distinguish and study each type of adaptation at individual level is impossible. It is obvious that in the process of the study it is necessary to individuate those types (aggregates, complexes) of adaptation, which have the most significant influence on the outcome indicator of the adaptation.

Different researchers individuate all sorts of factor groups: capital and temporary, objective and subjective, personal and industrial, global (socio-economic and political structure of society) and regional (naturalclimatic, degree of development of the social and life infrastructure, balance of labor resources). For example, T.N.Vershinina, exploring the industrial adaptation of workers, distinguishes between the following groups of factors (T.N.Vershinina presents the factors in the form of multi-component diagram illustrating the relationship between them):

personal: demographic characteristics, qualifications, experience, education, length of residence in the city, life experience, psychological characteristics, profession;

production: content and working conditions, work organization, living conditions, salary, opportunities for development, degree of maturity of the work microclimate;

factors outside production boundaries: system for professional orientation and professional selection, system for staff preparation and distribution, state of the labor resources, level of development of the social and life infrastructure in the region;

psycho-physical and socio-psychological factors: psychological and physical stress, interpersonal communication, life component.

The classification is detailed enough, but is complex and voluminous. Each of the demarcated factors contains another whole complex of factors, which are difficult to be classified, and it is not clear why specific factors are individuated and how each of them affects the adaptation.

The proposed factors are difficult to list and even more difficult to be studied. For example, the factor "demographic characteristics" may include many items and the „factors outside production" are innumerable. It can be assumed that the attempts to identify all factors in order to systematize the types of adaptations are doomed to failure, which questions the requirement for integrity in the study of the adaptation process. But this is not a ground for refusal of seeking ways to resolve the problem. The impossibility to identify all factors encourages researchers to examine the individual factors (or their aggregates). Thus $\mathrm{E}$. S. Balabanova uses four random factors: success in life, social parasitism, economic independence and law obedience, while S. G. Markovkina- only one. Naturally, the dependence of adaptation on a limited number of factors is also limited, even with the most appropriate choice of factors. No combination of factors, and even less an individual factor, can fully reflect the social adaptation. Limiting the number of factors, their arbitrary and nonsystematic distinction, does not allow to define them as measures of social adaptation (Banabakova, Georgiev, 2018I, pp. 462-467; Terziev, 2017b, pp.517-528; Terziev, 2017c; Hristov, 2018m, pp. 277-282; Terziev, Nichev, 2017d, p.152; Terziev, Nichev, 2017e, pp.846-850; Terziev, Nichev, 2017f, p.164; Terziev, 
Nichev, 2017g, pp.915-919; Terziev, Madanski, Georgiev, 2017h, pp.743-747; Terziev, Madanski, Georgiev, 2017i, pp.748-753; Terziev, Nichev, Stoyanov, Georgiev, 2017j, pp.690-694; Terziev, Latyshev, Georgiev, 2017k, pp.754-772; Terziev, Nikolay, Bogdanov, 2017l, pp.671-677; Terziev, Madanski, Kanev, 2017m, pp.1331-1346; Terziev, Madanski, Kanev, 2017n, pp.1355-1372; Terziev, Madanski, Kanev, 2017o, pp.1380-1393; Terziev, Madanski, Kanev, 2017p, pp.396-415; Terziev, 2017q, pp.641-653; Terziev, Nichev, 2017r, pp.627-630; Terziev, Madanski, Kanev, 2017s, pp.575-594; Terziev, 2017t, pp.22-28; Terziev, Nichev, 2017u, pp.646-658; Terziev, Nichev, 2017v, pp.659-670; Terziev, Madanski, 2017w, pp.610-625; Terziev, Madanski, 2017x, pp.917-937).

\section{CONCLUSION}

Another approach is to summarize, abstractize the factors, in result of which they become so vast that they have no independent meaning and require divisionto smaller components. A similar situation occurs in the case of forming of only two groups of factors. Asan example we can refer to the classification of $\mathrm{I}$. A. Georgieva, consisting of internal and external factors, which in turn are subdivided into tenths and hundreds of constituent elements.

It is impossible, even in theory, to take into account all the factors that affect (or may affect) the process of adaptation. This is not necessary, since not all factors determine the adaptation, but only few of them, which corresponds to the actual needs.

In its present shape theutilitarian needs classification contains seven complexes of needs: material (economic) for self-preservation, regulatory, reproduction (sexual), communicative, cognitive, self-fulfillment. Each of the complexes contains a range of personalneeds. And since socially oriented needs of the individual are associated with the social needs of society, the depth of research suggests the relationship between social adaptation and socialization, which is subject to our further research.

\section{REFERENCE LIST}

Terziev, Venelin. (2018a). Building a model of social and pshychological adaptation. // ADVED 2018- 4th International Conference on Advances in Education and Social Sciences Abstracts \& Proceedings, 1517 October 2018- Istanbul, Turkey, International Organization Center of Academic Research, www.ocerints.org, Istanbul, Turkey, 2018, pp. 228-236, ISBN: 978-605-82433-4-7.

Stefanov, S., Terziev, V., Banabakova, V. (2018b). The undertsanding of security in the postmodern society. // ADVED 2018- 4th International Conference on Advances in Education and Social Sciences Abstracts \& Proceedings, 15-17 October 2018- Istanbul, Turkey, International Organization Center of Academic Research, www.ocerints.org, Istanbul, Turkey, 2018, pp. 93-102, ISBN: 978-605-82433-4-7.

Stefanov, S., Terziev, V., Banabakova, V. (2018c). Levels of security and postmodern society. // ADVED 2018- 4th International Conference on Advances in Education and Social Sciences Abstracts \& Proceedings, 15-17 October 2018- Istanbul, Turkey, International Organization Center of Academic Research, www.ocerints.org, Istanbul, Turkey, 2018, pp. 111-119, ISBN: 978-605-82433-4-7.

Terziev, V., Stefanov, S., Banabakova, V. (2018d). Implementattion of the common european security and defence policy in the context of its military aspect. // ADVED 2018- 4th International Conference on Advances in Education and Social Sciences Abstracts \& Proceedings, 15-17 October 2018- Istanbul, Turkey, International Organization Center of Academic Research, www.ocerints.org, Istanbul, Turkey, 2018, pp. 120-131, ISBN: 978-605-82433-4-7.

Terziev, V., Stefanov, S., Banabakova, V. (2018e). Common european security and defence policy. // ADVED 2018- 4th International Conference on Advances in Education and Social Sciences Abstracts \& Proceedings, 15-17 October 2018- Istanbul, Turkey, International Organization Center of Academic Research, www.ocerints.org, Istanbul, Turkey, 2018, pp. 132-148, ISBN: 978-605-82433-4-7.

Terziev, Venelin. (2018f). Bulgarian experience in the development of social adaptation of military personnel, discharged from military service and their families. // ADVED 2018- 4th International Conference on Advances in Education and Social Sciences Abstracts \& Proceedings, 15-17 October 2018- Istanbul, Turkey, International Organization Center of Academic Research, www.ocerints.org, Istanbul, Turkey, 2018, pp. 213-227, ISBN: 978-605-82433-4-7.

Terziev, Venelin. (2018g). Opportunities of aplication of a competence-based approach in social adaptation 
of militaries discharged of service. // ADVED 2018- 4th International Conference on Advances in Education and Social Sciences Abstracts \& Proceedings, 15-17 October 2018- Istanbul, Turkey, International Organization Center of Academic Research, www.ocerints.org, Istanbul, Turkey, 2018, pp. 237-247, ISBN: 978-605-82433-4-7.

Terziev, Venelin. (2018h). Possible aspects of occupational and psychological adaptation of the military, discharged from military service and their families to a new activity life cycle. // ADVED 2018- 4th International Conference on Advances in Education and Social Sciences Abstracts \& Proceedings, 1517 October 2018- Istanbul, Turkey, International Organization Center of Academic Research, www.ocerints.org, Istanbul, Turkey, 2018, pp. 256-265, ISBN: 978-605-82433-4-7.

Terziev, Venelin. (2018i). Realities of implementing the social adaptation process of military personnel, discharged form service in Bulgaria. // ADVED 2018- 4th International Conference on Advances in Education and Social Sciences Abstracts \& Proceedings, 15-17 October 2018- Istanbul, Turkey, International Organization Center of Academic Research, www.ocerints.org, Istanbul, Turkey, 2018, pp. 266-276, ISBN: 978-605-82433-4-7.

Terziev, V., Latyshev, O., Georgiev, M. (2018j). The warehousing as an element of army logistics system in conditions of arctics (from experience of bulgarianrussian cooperation). // ADVED 2018- 4th International Conference on Advances in Education and Social Sciences Abstracts \& Proceedings, 1517 October 2018- Istanbul, Turkey, International Organization Center of Academic Research, www.ocerints.org, Istanbul, Turkey, 2018, pp. 248-255, ISBN: 978-605-82433-4-7.

Glushkov, P., Simeonov, S., Georgiev, M. (2018k). Method of determination of the diurnal energy consumption of the cadets from the Vasil Levski National Military university. ADVED 2018- 4th International Conference on Advances in Education and Social Sciences Abstracts \& Proceedings, 1517 October 2018- Istanbul, Turkey, International Organization Center of Academic Research, www.ocerints.org, Istanbul, Turkey, 2018, pp. 88-92, ISBN: 978-605-82433-4-7.

Banabakova, V., Georgiev, M. (2017a). Problems and perspectives in Military professional education and realization of cadets in Bulgaria. // Journal of Innovations and Sustainability, Innovations and Sustainability Academy. 3, 2017, N 4, pp. 37-47, ISSN 2367-8127 (CD-ROM), ISSN 2367-8151 (online).

Banabakova, V., Georgiev, M. (2018I). Military professional forming of the cadets at Vasil Levski National Military University. // Proceedings of INTCESS2018- 5th International Conference on Education and Social Sciences 5-7 February 2018- Istanbul, Turkey, International Organization Center of Academic Research, www.ocerints.org, Istanbul, Turkey, 2018, pp. 462-467, ISBN : 978-605-82433-2-3.

Terziev, Venelin. (2017b). Opportunities and trends in the development and the improvement processes in the Bulgarian military educational system. // 3rd Central \& Eastern European LUMEN International Conference, New Approaches in Social and Humanistic Sciences NASHS 2017, Chisinau, Republic of Moldova, June 8-10, 2017, 2018, pp.517-528, ISSN (print): 2601 - 2510, ISSN (on-line): 2601 2529, ISSN-L: 2601 - 2510, ISBN: 978-1-910129-15-9.

Terziev, Venelin. (2017c). Opportunities for improving the efficiencyof the socialadaptation of servicemen discharged from military service in Bulgaria. // Catalogue of the scientific, educational and methodical literature presented by authors at the I -XXXIV All-Russian book exhibitions held by Academy of Natural History, Exposition on the Frankfurter Buchmesse 2017, XXVII, Moskow, Academy of Natural History, 2017.

Hristov, Neno. (2018m). European intervention initiative vs common European army. ADVED 2018- 4th International Conference on Advances in Education and Social Sciences Abstracts \& Proceedings, 1517 October 2018- Istanbul, Turkey, International Organization Center of Academic Research, www.ocerints.org, Istanbul, Turkey, 2018, pp. 277-282, ISBN: 978-605-82433-4-7.

Terziev, V., Nichev, N. (2017d). Research on the management skills and abilities acquired in the military education system. // CBU International Conference Book of Abstracts March 22-24, Prague, Czech Republic, Innovations in Science and Education, 2017, ISBN 978-80-88042-09-9, p.152.

Terziev, V., Nichev, N. (2017e). Research on the management skills and abilities acquired in the military education system. // CBU International Conference Proceedings 2017, March 22-24, Prague, Czech Republic, Innovations in Science and Education, 2017, SSN 1805-997X (Print), ISBN 978-80-8804207-5 (Print edition), pp.846-850.

Terziev, V., Nichev, N. (2017f). Developing the readiness for the organizational activity of the cadets. // CBU 
International Conference Book of Abstracts March 22-24, Prague, Czech Republic, Innovations in Science and Education, ISBN 978-80-88042-09-9, p.164.

Terziev, V., Nichev, N. (2017g). Developing the readiness for the organizational activity of the cadets. // CBU International Conference Proceedings 2017, March 22-24, Prague, Czech Republic, Innovations in Science and Education, 2017, SSN 1805-997X (Print), ISBN 978-80-88042-07-5 (Print edition), pp.915-919.

Terziev, V., Madanski, V., Georgiev, M. (2017h). Offset implementation impact on technology transfer in Bulgaria. // Proceedings of ADVED 2017- 3rd International Conference on Advances in Education and Social Sciences 9-11 October 2017- Istanbul, Turkey, 2017, ISBN: 978-605-82433-0-9, pp.743-747.

Terziev, V., Madanski, V., Georgiev, M. (2017i). Offset as an economic operation and a trade practice. // Proceedings of ADVED 2017- 3rd International Conference on Advances in Education and Social Sciences 9-11 October 2017- Istanbul, Turkey, 2017, ISBN: 978-605-82433-0-9, pp.748-753.

Terziev, V., Nichev, N., Stoyanov, E., Georgiev, M. (2017j). A general principle of the development process of balanced scorecards as an instrument of control. // Proceedings of ADVED 2017- 3rd International Conference on Advances in Education and Social Sciences 9-11 October 2017- Istanbul, Turkey, 2017, ISBN: 978-605-82433-0-9, pp.690-694.

Terziev, V., Latyshev, O., Georgiev, M. (2017k). Building competencies for social work through continuing vocational training. // Proceedings of ADVED 2017- 3rd International Conference on Advances in Education and Social Sciences 9-11 October 2017- Istanbul, Turkey, 2017, ISBN: 978-605-82433-0-9, pp.754-772.

Terziev, V., Nikolay, N., Bogdanov, P. (2017l). Comparative analysis of the formation of military professional skills in the cadets to be trained in logistics specializations. // Proceedings of ADVED 2017- 3rd International Conference on Advances in Education and Social Sciences 9-11 October 2017- Istanbul, Turkey, 2017, ISBN: 978-605-82433-0-9, pp.671-677.

Terziev, V., Madanski, V. Kanev, D. (2017m). Entry opportunities in the Bulgarian military-educational system. // Sport, Education and Society, Taylor \& Francis, 22, 2017, N 8(2), Source Normalized Impact per Paper (SNIP): 1.459 SCImago Journal Rank (SJR): 1.005 Impact factor: 1.269 Ranking: 60/230 (Education \& Educational Research), 20/44 (Hospitality, Leisure, Sport and Tourism), 51/82 (Sport Sciences), Print ISSN: 1357-3322 Online ISSN: 1470-1243, pp.1331-1346.

Terziev, V., Madanski, V., Kanev, D. (2017n). Condition and capabilities of the military-educational system of the Republic of Bulgaria. // Sport, Education and Society, Taylor \& Francis, 22, 2017, N 8(2), Source Normalized Impact per Paper (SNIP): 1.459 SCImago Journal Rank (SJR): 1.005 Impact factor: 1.269 Ranking: 60/230 (Education \& Educational Research), 20/44 (Hospitality, Leisure, Sport and Tourism), 51/82 (Sport Sciences), Print ISSN: 1357-3322 Online ISSN: 1470-1243, pp.1355-1372.

Terziev, V., Madanski, V., Kanev, D. (2017o). Directions for improvement of the military-educational system and its contribution for strengthening national security and the defence of the country. // Sport, Education and Society, Taylor \& Francis, 22, 2017, N 8(2), Source Normalized Impact per Paper (SNIP): 1.459 SCImago Journal Rank (SJR): 1.005 Impact factor: 1.269 Ranking: 60/230 (Education \& Educational Research), 20/44 (Hospitality, Leisure, Sport and Tourism), 51/82 (Sport Sciences), Print ISSN: 1357-3322 Online ISSN: 1470-1243, pp.1380-1393.

Terziev, V., Madanski, V., Kanev, D. (2017p). Entry opportunities in the bulgarian military-educational system and ensuring of civil rights. // IJAEDU- International E-Journal of Advances in Education, 3, 2017, N 8, e-ISSN:2411-1821, pp.396-415.

Terziev, Venelin. (2017q). The needs of continuing vocational training of social work specialists providing social services. // Proceedings of SOCIOINT 2017- 4th International Conference on Education, Social Sciences and Humanities 10-12 July 2017- Dubai, UAE, 2017, ISBN: 978-605-82433-1-6, pp.641-653.

Terziev, V., Nichev, N. (2017r). Analysis of the environment for military educational system functioning and its impact on the preparation of cadets for military professional activities in the republic of Bulgaria. // Proceedings of SOCIOINT 2017- 4th International Conference on Education, Social Sciences and Humanities 10-12 July 2017- Dubai, UAE, 2017, ISBN: 978-605-82433-1-6, pp.627-630.

Terziev, V., Madanski, V., Kanev, D. (2017s). Entry opportunities in the bulgarian military-educational system and ensuring of civil rights. // Proceedings of SOCIOINT 2017- 4th International Conference on Education, Social Sciences and Humanities 10-12 July 2017- Dubai, UAE, 2017, ISBN: 978-605- 
82433-1-6, pp.575-594.

Terziev, Venelin. (2017t). National security of the republic of Bulgaria. // International Journal of Management and Applied Science, 3, 2017, N 4, ISSN: 2394-7926, pp.22-28.

Terziev, V., Nichev, N. (2017u). Research of the value orientation and structural peculiarities of management activitiesofcadets in the course of military professional training. // Proceedings of the VII International Academic Congress „Fundamental and Applied Studies in EU and CIS Countries” (United Kingdom, Cambridge, England, 26-28 February 2017), Cambridge University Press, 7, 2017, ISBN: 978-0-87583597-4, pp.646-658, Source Normalized Impact per Paper (SNIP): 5.192 SCImago Journal Rank (SJR): 5.186 Impact factor: 7.549 .

Terziev, V., Nichev, N. (2017v). Research of the motivation for management activities of cadets in the course of their military professional training. // Proceedings of the VII International Academic Congress „Fundamental and Applied Studies in EU and CIS Countries” (United Kingdom, Cambridge, England, 26-28 February 2017), Cambridge University Press, 7, 2017, ISBN: 978-0-875-83597-4, pp.659-670, Source Normalized Impact per Paper (SNIP): 5.192 SCImago Journal Rank (SJR): 5.186 Impact factor: 7.549 .

Terziev, V., Madanski, V. (2017w). Guidelines for development of military education system in Bulgaria. // Proceedings of the VII International Academic Congress "Fundamental and Applied Studies in EU and CIS Countries" (United Kingdom, Cambridge, England, 26-28 February 2017), Cambridge University Press, ISBN: 978-0-875-83597-4, 7, 2017, pp.610-625, Source Normalized Impact per Paper (SNIP): 5.192 SCImago Journal Rank (SJR): 5.186 Impact factor: 7.549.

Terziev, V., Madanski, V. (2017x). Development of military education system in Bulgaria. // American Journal of Education, The University of Chicago Press, 2017, 123, 2017, N 4 (2), ISSN: 0195-6744, pp.917937, Source Normalized Impact per Paper (SNIP): 1.653, SCImago Journal Rank (SJR): 2.243. 